\title{
Ethylene-Octene-Copolymer as an alternative to Styrene-Butadiene-Styrene bitumen modifier
}

\author{
A. Riekstins \\ Faculty of Civil Engineering, Department of Roads and Bridges, Riga Technical University, Riga, Latvia \\ SJSC Latvian State Roads, Riga, Latvia \\ V. Haritonovs \\ Faculty of Civil Engineering, Department of Roads and Bridges, Riga Technical University, Riga, Latvia \\ R. Merijs-Meri \& J. Zicāns \\ Faculty of Materials Science and Applied Chemistry, Institute of Polymer Materials, Riga Technical \\ University, Riga, Latvia
}

\begin{abstract}
This paper investigates the perspective of the use of an unfamiliar bitumen modifier - Ethylene-Octene-Copolymer (EOC) - for the production of polymer modified bitumen (PMB). For the study, bitumen 70/100 was modified at a laboratory with EOC and SBS modifiers. From the industrial bitumen manufacturer, SBS modified bitumen 45/80-55 (SBS fact) was obtained. The rheological properties of the laboratory-produced and the industrially-produced bitumen were compared. In addition to the industrial binder, two laboratoryproduced PMB compositions with the lowest viscosity on the one hand $(70 / 100+2 \% \mathrm{EOC})$ and the highest viscosity on the other hand $(70 / 100+4 \% \mathrm{SBS})$ were used to design asphalt mixtures. The following performance tests were used to evaluate physical properties of the obtained asphalt mixtures: wheel tracking test (WTT), thermal strain restricted specimen test (TSRST) and four-point bending test (4PB). In comparison to the laboratory-produced SBS modified bituminous binder containing asphalt mixture the EOC modified counterpart demonstrates a better low-temperature cracking behaviour, approaching the values characteristic of the SBS fact bound asphalt mixture. In its turn, rutting and fatigue resistance of the SBS lab modified bitumen containing asphalt mixtures are higher in comparison to EOC lab modified systems. Even higher fatigue resistance of SBS fact containing systems is evidently connected with a better mixing quality due to technical aspects ensured in bitumen production plant.
\end{abstract}

Keywords: polymer modified bitumen, ethylene-octene-copolymer, styrene-butadienestyrene, asphalt mixture, performance tests

\section{INTRODUCTION}

Increasing traffic intensity, environmental concerns and limited budget keep industry and academicians searching for more sustainable asphalt mixtures. Bitumen as the most expensive constituent of asphalt directly affects all performance properties of the layer. Through bitumen modification, it is possible to improve the properties of asphalt binder (Singh, Chopra, Jain, Kaur, \& Kamotra, 2019). As modifiers are not cheap, they noticeably impact the price of the end product and therefore they are mostly used on high traffic intensity roads 
(Brasileiro, Moreno-Navarro, Tauste-Martínez, Matos, \& Rubio-Gámez, 2019) and just in the top layer. Currently, the most used modifier on the market is styrene-butadiene-styrene (SBS) although it has several drawbacks such as poor storage stability and low ageing resistance (Ren, Liu, Fan, Wang, \& Erkens, 2019; Zhu, Birgisson, \& Kringos, 2014). Because of the huge demand, the price of SBS elastomer has significantly increased in recent years and the forecast is that it will continue to grow thus affecting the price of asphalt. (Market Watch, 2020)

One way to reduce the costs is to use thinner asphalt layer(s) so that less bitumen and also a modifier are needed. In Latvia, the thickness of the top layer is usually designed to be 35$40 \mathrm{~mm}$. The main aim of the wearing course is to provide a smooth surface and load transfer. The thickness of the top layer could be optimized if better quality aggregates and modified bitumen are used (Kragh et al., 2011) in case the reduction of the wearing course is not compensated by another thicker structural layer. Very thin asphalt concrete (BBTM) is a promising alternative to conventional asphalt mixtures (A. Riekstins, Haritonovs, Abolins, Straupe, \& Tihonovs, 2019; Arturs Riekstins, Haritonovs, \& Straupe, 2020). BBTM could be used on high-intensity roads because of the durable mineral carcass. Typically, the thickness of the wearing course is 20 to $30 \mathrm{~mm}$. By using BBTM instead of conventional asphalt mixtures such as asphalt concrete (AC) or stone mastic asphalt (SMA), it is possible to reduce the consumption of aggregates and binder up to $50 \%$. Such reduction is particularly important for countries and regions that import aggregates and/or bitumen. However, the use of BBTM mostly increases the use of PMB. Thus, it is not possible to avoid the use of polymers, but it is possible to find an alternative to SBS.

A cheaper and more promising polymer might be ethylene-octene copolymer (EOC) which has not been used for commercial modification yet. In the authors' previous studies, EOC showed improved bitumen high-temperature properties as well as ageing resistance, suggesting that this thermoplastic elastomer has the potential to be used as a bitumen modifier. (MerijsMeri, Abele, Zicans, \& Haritonovs, 2019; Zicans, Ivanova, Merijs-Meri, Berzina, \& Haritonovs, 2019).

Bitumen modification parameters and technologies have a great influence on the performance of asphalt binder. It is well known that bitumen modification in the factory is done by colloidal mixers, while preparation of bituminous compositions in the laboratory is usually done by high shear mixers. A direct comparison can give false information about the efficiency of a modifier. Consequently, in order to develop an efficient alternative asphalt binder, it is relevant but at the same time, scientists should be careful to directly compare the properties of the laboratory-produced binders with industrially manufactured commercial counterparts.

\section{OBJECTIVE}

In this research, the performance of the EOC modified bitumen binder in comparison to the traditional SBS, manufactured both at laboratory and industrial scales was evaluated. The comparison was done on two levels - (1) polymer modified bitumen (PMB) binder testing, (2) asphalt mixture testing. For this purpose, a dynamic shear rheometer (DSR), a wheel tracking test (WTT), a thermal stress restrained specimen test (TSRST) and a four-point bending test (4PB) were used.

\section{MATERIALS AND METHODS}

A flowchart of the experimental program is demonstrated in Figure 1. Initially, two types of PMB binder were developed at the laboratory. In comparison to traditionally used SBS, EOC was used as a bitumen modifier. The content of either of the polymer modifiers was fixed at 2 wt. $\%$ and 4 wt. $\%$. As a reference, industrially produced PMB 45/80-55 was used, in which SBS content could be estimated in the range of 3-4 wt.\% independence on the used test procedure (Ratajczak \& Wilmański, 2020). At first, rheological properties were tested and evaluated for all 
the obtained bitumens. Based on the rheological properties for further investigations bituminous composition with 4 wt.\% of SBS (in general, the highest viscosity and shear modulus at the lowest phase angle value over the temperature range investigated) and $2 \mathrm{wt} . \%$ of EOC (in general, the lowest viscosity and shear modulus at the highest phase angle value over the temperature range investigated) were chosen to characterize the influence of the laboratory developed modified bitumens on the performance of asphalt mixtures. This allowed evaluating the effect of the addition of both the lowest viscosity and the highest viscosity PMB on the performance of the asphalt mixtures. Volumetric tests of the designed asphalt mixtures were performed to make sure that air voids are within the planned range. Subsequently, mixtures that met the requirements were tested for the following performance-based tests: WTT, TSRST, 4PB.

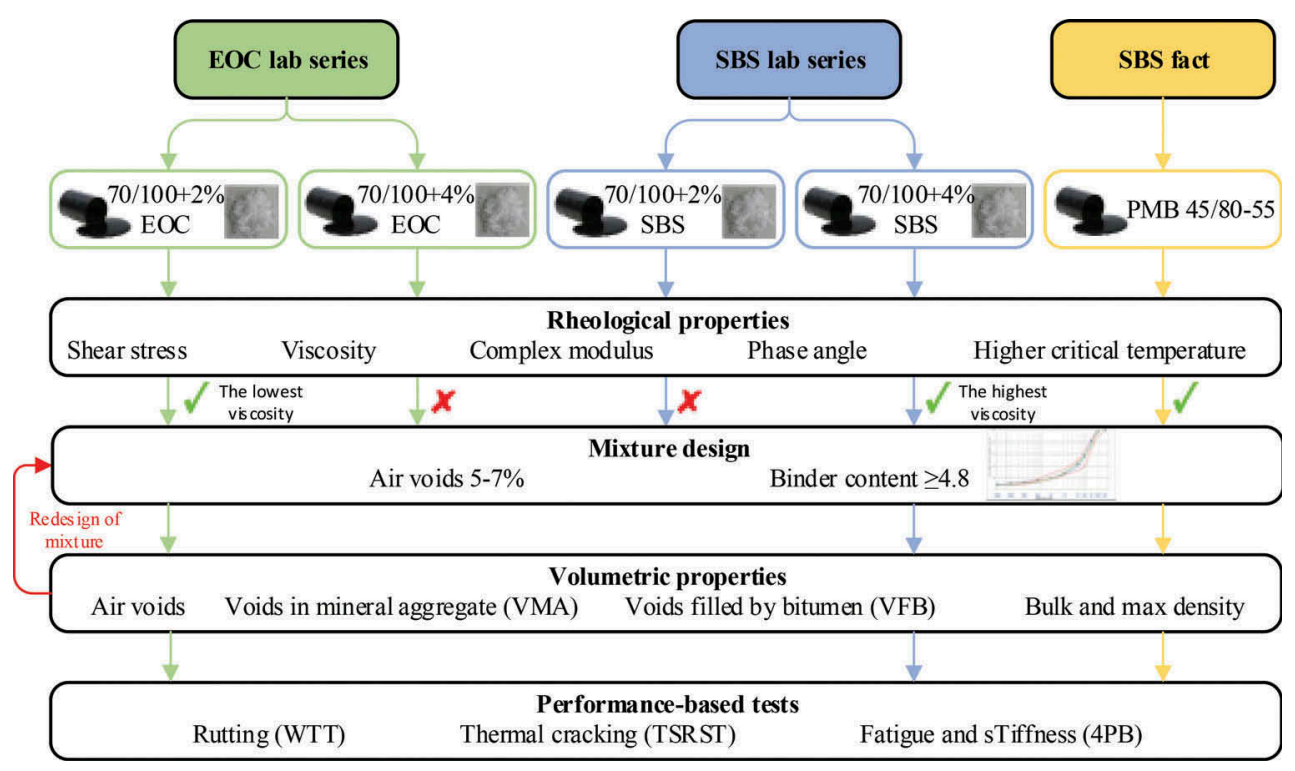

Figure 1. Flowchart of the experimental program.

\subsection{Materials}

\subsubsection{Bitumen}

For the needs of the research, two different binders were obtained - bitumen 70/100 and PMB 45/ 80-55. Bitumen 70/100 was used for modification purposes and PMB for comparison purposes.

\subsubsection{Modifiers}

Two different elastomers - linear SBS and EOC with 1-octene group content of 38\% - were used as polymeric modifiers. SBS is the most popular bitumen modifier on the market. On the other hand, EOC is not currently used to modify bitumen commercially. Both SBS and EOC are elastomers, showing low glass transition temperatures and high ultimate elongations; EOC, however, is less viscous. Images of SBS and EOC modifiers are shown in Table 1.

\subsubsection{Aggregates}

For the production of asphalt mixtures crushed quartz-diorite fractions of $8 / 11 \mathrm{~mm}, 5 / 8 \mathrm{~mm}$ and $0 / 5 \mathrm{~mm}$ were used. Dolomite flour was used as a filler. All materials meet the highest level (S-1 class) of the Latvian Road specification requirements (VAS "Latvijas Valsts celii", 2019). 
Table 1. Comparison of SBS and EOC modifiers.

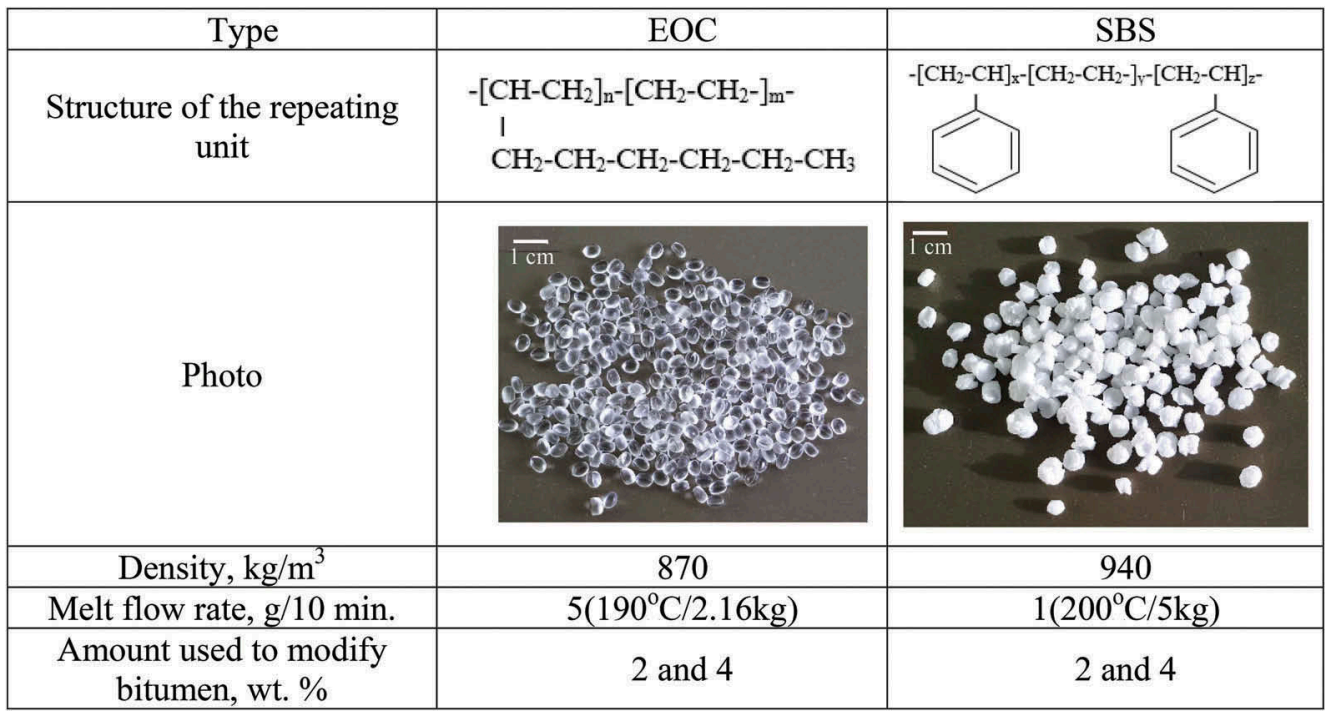

\subsection{Methods}

\subsubsection{Preparation of PMB binders}

PMB binders with 2 wt. $\%$ and 4 wt. $\%$ of either EOC or SBS were prepared as follows: initially, the bitumen was heated up to $140^{\circ} \mathrm{C}$ in a laboratory oven, then the vessel with the melted bitumen was placed in a silicone oil bath and, when the temperature reached $170^{\circ} \mathrm{C}$, the elastomer was gradually added and mixing was continued for 3 hours at $185-188^{\circ} \mathrm{C}$ at the speed of 6000 $7000 \mathrm{rpm}$ by using Silverson L5M-A high shear laboratory mixer equipped with a square hole screen. Thus, the prepared modified bitumen binders, were poured in a separate vessel, and kept at sub-zero temperatures until measurements were taken to avoid settling. The process of obtaining the industry and the laboratory-produced bituminous binders is schematically depicted in Figure 2 for SBS fact and Figure 3 for SBS lab and EOC lab.

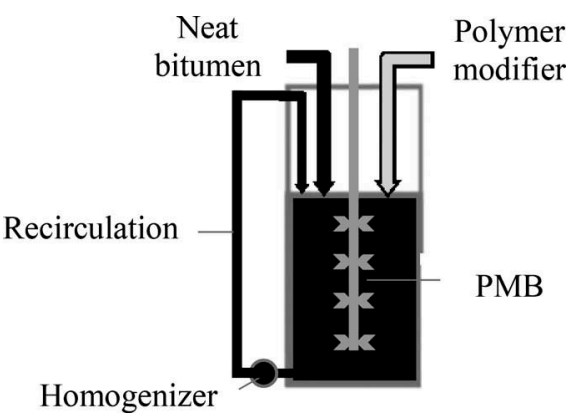

Figure 2. PMB made by plant equipment.

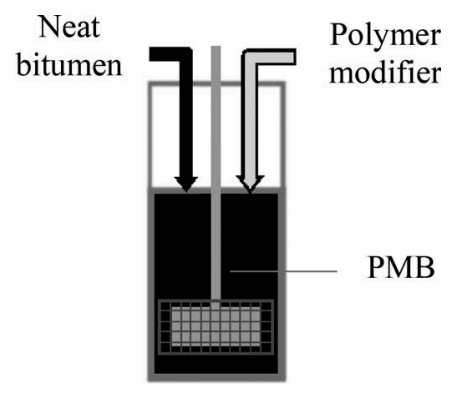

Figure 3. PMB made by high shear laboratory mixer. 


\subsubsection{Mixture design}

Granulometric curves of mixtures are demonstrated in Figure 4. According to the experimental program, depicted in Figure 1, three mixtures were compared differing by the polymer binder used and its content - 70/100+2wt.\%EOC (EOC lab), 70/100+2wt.\%SBS (SBS lab) and 45/80-55 (SBS fact). Based on the previous research results (A. Riekstins et al., 2019) two most perspective granulometric compositions were selected (solid lines in Figure 4). The same granulometric distribution was selected for EOC lab and SBS fact. A slightly different granulometric distribution was selected for laboratory-made SBS PMB. The target air voids content for all the mixtures was within $5 \%$ and $7 \%$. Thus, it was obtained that the optimal bitumen content for EOC lab and SBS fact mixtures is $5.2 \%$ and for SBS lab mixture $-4.8 \%$.

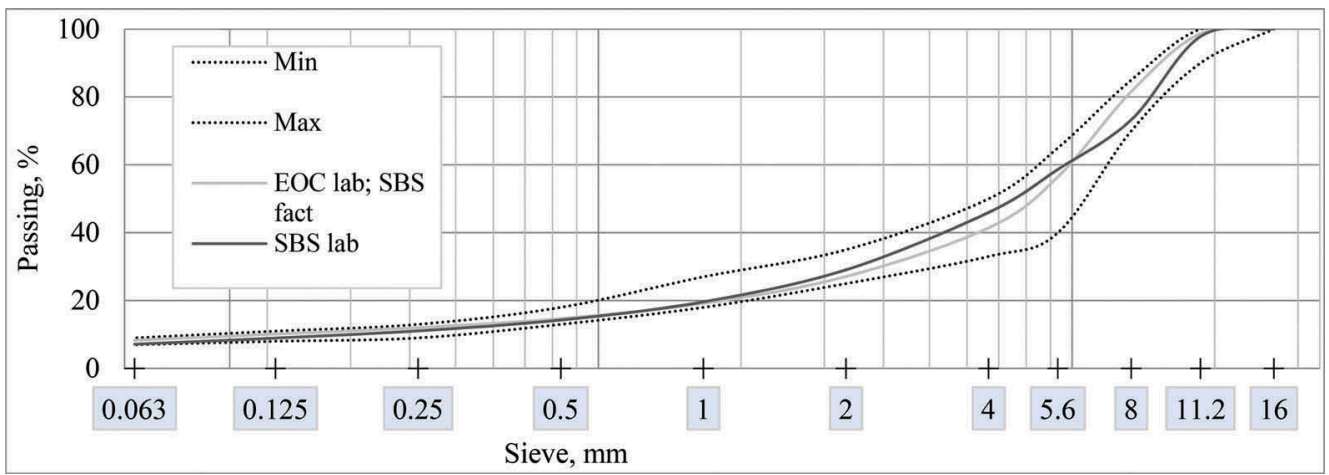

Figure 4. Granulometric distribution of asphalt mixtures. The dotted lines show granulometric distribution limits.

\subsubsection{Rheological properties of bituminous binders}

Rheological properties of commercial bitumen and the laboratory developed bituminous compositions with EOC and SBS were tested according to AASHTO T315 by using a $25 \mathrm{~mm}$ plate-plate configuration with a $1 \mathrm{~mm}$ gap. In brief, the tests were performed at $12 \%$ shear strain by increasing temperatures with a step of $6 \mathrm{PPP}^{\circ} \mathrm{PPPC}$ until the critical temperature at which the value of $\left|\mathrm{G}^{*}\right| / \sin (\delta)$ decreased below $1 \mathrm{kPa}$.

\subsubsection{Volumetric properties of asphalt mixtures}

All Marshall samples with a diameter of $100 \mathrm{~mm}$ were made according to EN 12697-30. The impact compactor was used, and 50 blows were applied to each side. Samples were compacted at $150^{\circ} \mathrm{C}$. Bulk density, maximum density, air voids, voids in mineral aggregate (VMA), voids filled by bitumen (VFB) and binder content were measured.

\subsubsection{Rutting resistance}

WTT was used to evaluate the rutting resistance of the developed asphalt mixtures. The test was performed according to EN 12697-22. The specimens were tested according to procedure $\mathrm{B}$ at $60^{\circ} \mathrm{C}$ degrees in the air by a small device. The design thickness of the wearing course was $25 \mathrm{~mm}$. Referring to the standard, the nominal thickness of the samples with a maximum particle size of $11 \mathrm{~mm}$ should be at least $40 \mathrm{~mm}$. Therefore, a two-layer specimen system was used to evaluate the ruts (see Figure 5). Firstly, the base course with the thickness of $60 \mathrm{~mm}$ was compacted. A tack coat layer was applied on the top of the base layer. Emulsion with a residual bitumen content of $60 \%$ was used. Finally, BBTM layer was compacted on top of the base layer. The samples were tested under $700 \mathrm{~N}$ moving wheel cyclic load at the rate of 26.5 cycles per minute. For each sample, 20000 passes (10000 cycles) were made. Proportional rut depth $\left(\mathrm{PRD}_{\mathrm{AIR}}\right)$ and wheel tracking slope (WTS) were recorded. 


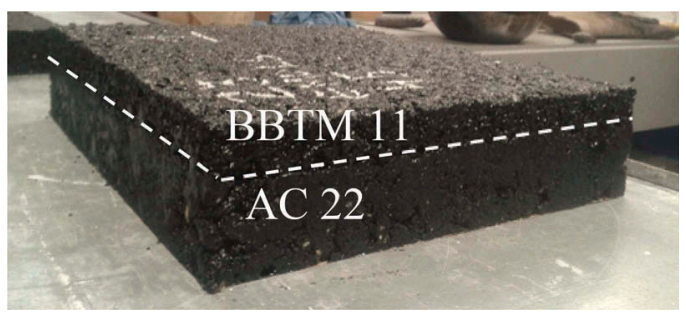

Figure 5. Two-layer specimen system for WTT.

\subsubsection{Low-temperature resistance}

TSRST was used to detect the ability of mixtures to resist thermal stresses when ambient temperature is decreased by a constant rate. The test was performed according to EN 12697-46. The starting temperature of the test was $20^{\circ} \mathrm{C}$ and it was lowered with the rate of $10^{\circ} \mathrm{C} / \mathrm{h}$. For each mixture, a slab $(320 \times 260 \times 90)$ was compacted by the roller compactor according to EN 12697-33. Two prismatic samples were cut out with the dimensions $40 \times 40 \times 160$. Failure stress and failure temperature were recorded.

\subsubsection{Fatigue and stiffness}

$4 \mathrm{~PB}$ test was used to evaluate fatigue resistance and stiffness of asphalt mixtures. The fatigue resistance test was performed according to EN 12697-24 and the stiffness test according to EN 12697-26. Both of the tests were done at $+10^{\circ} \mathrm{C}$. For each mixture, one slab with the dimensions $420 \times 320 \times 90 \mathrm{~mm}$ was compacted by roller compactor according to EN 12697-33. Four beams were cut out from each slab with the dimensions $50 \times 50 \times 420 \mathrm{~mm}$. First, the stiffness was tested for all beams. For the stiffness test, 1000 cycles were applied at the constant deformation amplitude of $50 \mu \mathrm{m} / \mathrm{m}$ (microstrain). Small deformation amplitude and a low number of cycles were assumed not to damage the investigated samples; therefore, the same beams were tested to fatigue resistance. Relative deformation for each mixture was individual and was based on the first beam test result (relative deformation for the samples ranged from 200 to $450 \mu \mathrm{m} / \mathrm{m}$ ). Fatigue resistance and stiffness were compared.

\section{RESULTS AND DISCUSSION}

\subsection{Bitumen rheological properties}

Rheological properties of 70/100, EOC and SBS modified virgin bitumen compositions, as well as virgin SBS fact, measured at various temperatures within a linear viscoelasticity region (LVER), are summarized in Table 2. The effects of UV irradiation and temperature of the properties of laboratory modified bituminous binders have been reported elsewhere (Zicans et al, 2019), where it was concluded that using these ageing protocols allowed to estimate the ageing of bitumen by obtaining comparable results to standard RTFOT tests and real aged bitumen. In the current manuscript, only the results of rheological properties of virgin PMB binders are reported as the research on the presented systems continues. 
Table 2. Bitumen rheological properties.

\begin{tabular}{llllll}
\hline $\begin{array}{l}\text { Param. T, } \\
\text { PPP०PPPC }\end{array}$ & $\begin{array}{l}\text { Bitumen } \\
\text { composition }\end{array}$ & $\begin{array}{l}\text { Shear stress, } \\
\mathrm{Pa}\end{array}$ & $\begin{array}{l}\text { Viscosity, } \\
\mathrm{Pa} \mathrm{s}\end{array}$ & $\begin{array}{l}\text { Shear modulus, } \\
\mathrm{kPa}\end{array}$ & $\begin{array}{l}\text { Phase shift angle, } \\
\mathrm{deg}\end{array}$ \\
\hline \multirow{6}{*}{64} & 167 & 139 & 1.386 & 84 \\
& $70 / 100$ & 265 & 2.647 & 82 \\
& $70 / 100+2 \%$ EOC & 319 & 281 & 2.811 & 79 \\
& $70 / 100+2 \%$ SBS & 340 & 460 & 4.598 & 78 \\
& $70 / 100+4 \%$ EOC & 554 & 442 & 4.420 & 69 \\
& $70 / 100+4 \%$ SBS & 533 & 525 & 5.251 & 65 \\
& PMB 45/80-55 & 633 & 67 & 0.673 & 86 \\
70 & $70 / 100$ & 130 & 1.302 & 84 \\
& $70 / 100+2 \%$ EOC & 157 & 137 & 1.369 & 81 \\
& $70 / 100+2 \%$ SBS & 165 & 236 & 2.355 & 81 \\
& $70 / 100+4 \%$ EOC & 284 & 242 & 2.420 & 71 \\
& $70 / 100+4 \%$ SBS & 292 & 295 & 2.945 & 66 \\
76 & PMB 45/80-55 & 355 & 66 & 0.658 & 86 \\
& $70 / 100+2 \%$ EOC & 79 & 69 & 0.694 & 83 \\
& $70 / 100+2 \%$ SBS & 84 & 123 & 1.229 & 83 \\
& $70 / 100+4 \%$ EOC & 148 & 138 & 1.381 & 73 \\
82 & $70 / 100+4 \%$ SBS & 167 & 171 & 1.710 & 67 \\
88 & PMB 45/80-55 & 206 & 66 & 0.622 & 85 \\
& $70 / 100+4 \%$ EOC & 80 & 82 & 0.822 & 73 \\
& $70 / 100+4 \%$ SBS & 99 & 101 & 1.013 & 69 \\
& PMB 45/80-55 & 122 & 61 & 0.609 & 71 \\
\hline
\end{tabular}

As it is demonstrated all the polymer-modified bituminous compositions show a higher shear stress, viscosity and shear modulus values along with lower phase shift angle values, denoting a more structured system (see Figure 6). In comparison, the introduction of SBS ensured larger increments of viscosity and shear modulus and correspondingly larger decrements of phase shift angle values than EOC modified compositions. As a result, the rheological properties of SBS based systems were closer to the commercial polymer-modified bitumen. This is easily explained by viscosity values of neat polymer modifiers, the viscosity of EOC being considerably lower than that of SBS. Another reason for this is differences in macromolecular structures of the used polymers, the structure of EOC being more linear. Consequently, the addition of EOC to bitumen in general leaves a smaller impact on the flowability of the composition. It is also worth mentioning that the rheological behaviour of the investigated bituminous binders was also influenced by the fact that the tests were performed over the temperature range, below the glass transition of styrene moieties in SBS and at or above melting of crystalline phase of $\mathrm{EOC}\left(\mathrm{ca} 40-70^{\circ} \mathrm{C}\right)$.

The temperature susceptibility of the investigated bituminous systems also improved upon the addition of polymer modifier, especially SBS. The temperature susceptibility of the laboratory modified $70 / 100+4 \%$ SBS system was rather close to that of commercial polymermodified bitumen.

Higher critical temperatures of the investigated bituminous systems can be derived from | $\mathrm{G}^{*} / \mathrm{sin}$ (delta) plots. As one can see, the critical temperature is considerably increased (by $16 \mathrm{PPP}^{\circ} \mathrm{PPPC}$ ) upon the introduction of a polymer modifier within the system. As already expected, the higher increment was ensured by the addition of the SBS modifier. Nevertheless, 


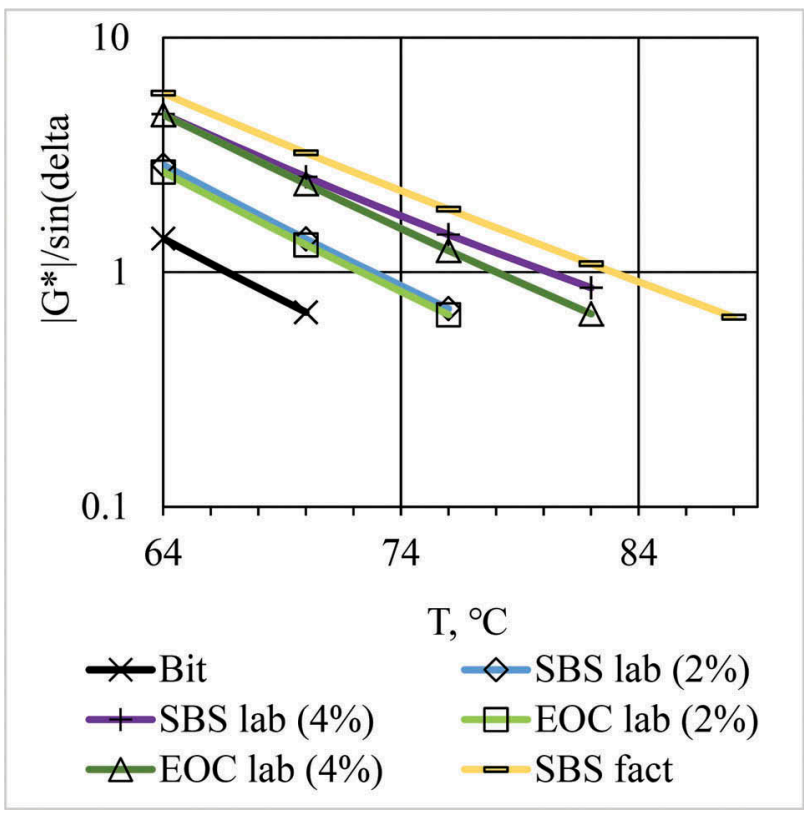

Figure 6. Higher critical temperature of neat bitumen 70/100 (Bit), SBS fact, as well as SBS lab and EOC lab-based systems. In the brackets mass percentage of the polymer is given.

it is clearly shown that also EOC modifier ensures a certain increment in rutting resistance of the $70 / 100$ grade bitumen.

\subsection{Physical properties}

Conventional volumetric test results are summarized in Table 3. Similar bulk and maximum densities were observed for all the mixtures. Mixtures were designed so that air voids are within the limit of 5 to $7 \%$. The obtained SBS fact obtained slightly lower air void content by $0.6 \%$ than mixture EOC lab that was with the same bitumen content and granulometric composition. The highest air void content of $6.9 \%$ was obtained by the mixture SBS lab. Relatively low air void content was chosen for BBTM mixtures because of climatic conditions. In Latvia, many freeze-thaw cycles can be observed around a year which could affect the stiffness and service life of the mixture with high air void content (Teltayev, Rossi, Izmailova, \& Amirbayev, 2019). Another drawback is the wide usage of studded tyres (Kingdom, 2014; Kragh et al., 2011). Both factors negatively affect the properties of high porosity mixtures.

Table 3. Volumetric properties of asphalt mixtures.

\begin{tabular}{llll}
\hline \multicolumn{1}{c}{ Parameter } & EOC lab & SBS lab & SBS fact \\
\hline${\text { Bulk density, } \mathrm{Mg} / \mathrm{mPPP}^{3}}^{3}$ & 2.373 & 2.373 & 2.393 \\
Max density, Mg/mPPP & 2.539 & 2.548 & 2.542 \\
Air voids, \% & 6.5 & 6.9 & 5.9 \\
VMA, \% & 18.9 & 18.1 & 18.2 \\
VFB, \% & 65.8 & 61.9 & 67.3 \\
Binder content, \% & 5.2 & 4.8 & 5.2 \\
\hline
\end{tabular}




\subsection{Rutting performance}

Rutting resistance results are shown in Figure 7. All the mixtures showed a similar tendency of rut development. Mixture SBS fact with a rut depth of $3.8 \mathrm{~mm}$ and WTS with the value of $0.11 \mathrm{~mm} / 1000$ cycles demonstrated the best rutting resistance among the investigated asphalt mixtures. SBS lab showed a slightly weaker result with the rut depth of $4.3 \mathrm{~mm}$ and the WTS value of $0.13 \mathrm{~mm} / 1000$ cycles. EOC lab showed the lowest rutting resistance with the rut depth of $4.9 \mathrm{~mm}$ and the WTS value of $0.15 \mathrm{~mm} / 1000$ cycles. Overall, huge differences between mixtures were not observed.

Currently in Latvia BBTM wearing course is not specified but in the Road Specifications, two requirements are set for conventional used wearing courses (AC and SMA):

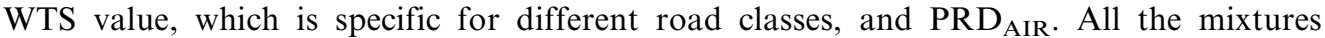
correspond to the second-highest road class according to Latvian State Roads (LSR) Road Specifications (the number of heavy trucks in 24 hours is up to 2000) (VAS "Latvijas Valsts celii", 2019), at the same time, only SBS fact meets PRD AIR requirement of $16 \%$ (4 mm rut depth for a $25 \mathrm{~mm}$ thick sample). The obtained results confirm findings in the literature that BBTM wearing course could be used on high traffic intensity roads (A. Riekstins et al., 2019; Sol-Sánchez, García-Travé, Ayar, Moreno-Navarro, \& RubioGámez, 2017). It should also be reminded that usually the evaluation of rutting resistance is not done for a two-layer specimen system, therefore the results of the WTS, in this case, reflect the ability of both the top layer and the bottom layer to withstand permanent deformations.

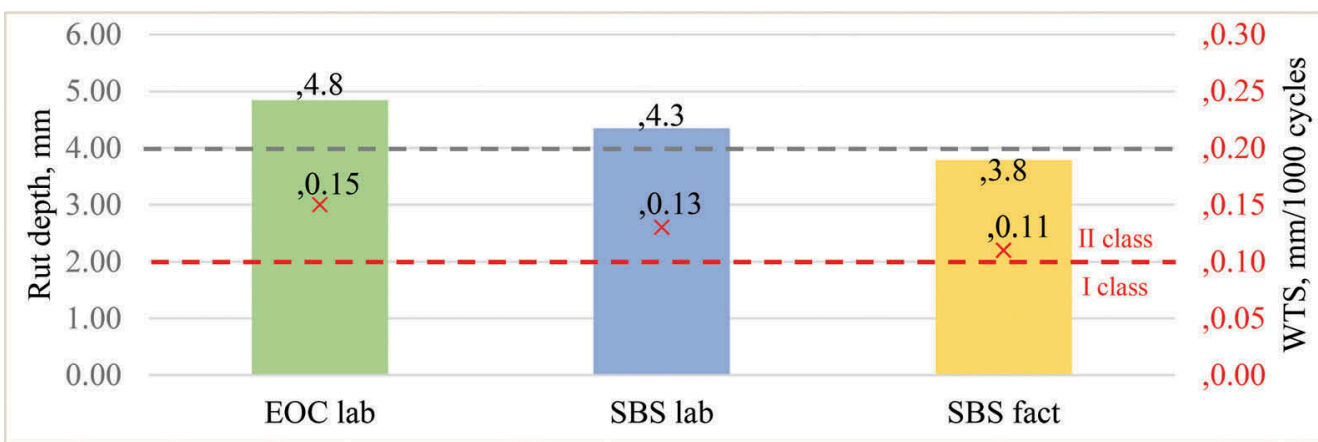

Figure 7. Rutting resistance results of asphalt mixtures. The grey dashed line shows the PRD requirement of wearing course. The red dashed line shows the compliance of asphalt mixtures into classes.

\subsection{Thermal cracking}

Results from the TSRST test are depicted in Figure 9. All the mixtures showed very similar results with the critical cracking temperature between $-26.0^{\circ} \mathrm{C}$ and $-27.1^{\circ} \mathrm{C}$ and with a slightly larger difference in critical strength between 5.000 MPa and 6.028 MPa. The results show that samples of SBS fact bound mixture broke at the lowest temperature of $-27.1^{\circ} \mathrm{C}$ and at the highest stress of $6.028 \mathrm{MPa}$ in comparison to other mixtures obtained. Both laboratory-made mixtures demonstrated very similar results even if different modifiers (SBS and EOC) and concentrations ( $4 \%$ and $2 \%$ ) were used. SBS lab demonstrated the weakest result most likely because of lower bitumen content and different granulometric composition. From different studies, it is known that bitumen content and granulometric composition directly influence the low-temperature performance of a mixture (Isacsson \& Zeng, 1998; Mollenhauer \& Tušar, 2016). 
Overall, all BBTM mixtures showed very good resistance to thermal cracking. In Latvia in the future, it is planned to implement TSRST as a quality control test for asphalt mixtures. Based on local weather conditions it is planned to use a requirement of $-22.5^{\circ} \mathrm{C}$ for all types of the wearing courses. Convincingly, all BBTM mixtures surpass the proposed requirement.

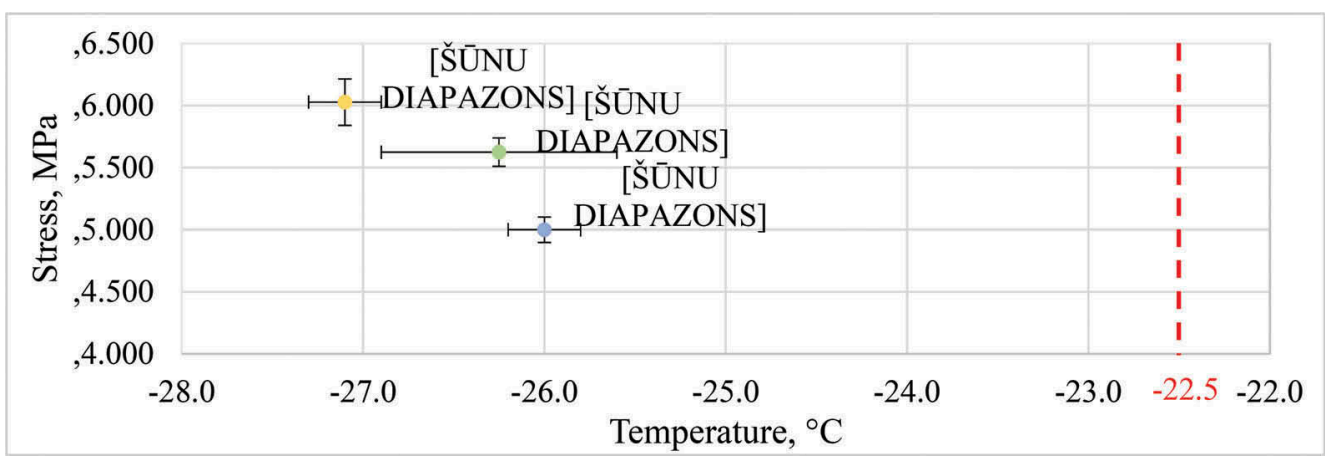

Figure 8. TSRST cracking temperatures for all PMB asphalt mixtures. The red dashed line shows the requirement of minimal cracking temperature.

\subsection{Stiffness and fatigue}

Stiffness and fatigue test results are illustrated in Figure 9 and Figure 10. Contrary to the results of the previous physical properties (rutting and thermal cracking) difference between asphalt mixtures produced by laboratory and industrially manufactured bitumen are much higher. SBS fact shows significantly higher fatigue strength then SBS lab and EOC lab (see Figure 10). What's more SBS fact also showed a better ability to withstand higher strain amplitudes. The main reason for that might be a more elastic and less stiff binder. SBS fact in comparison to EOC lab and SBS lab is less stiff $(9762 \mathrm{MPa}$ versus $10212 \mathrm{MPa}$ and $11043 \mathrm{MPa}$ ). Other important factors that may influence fatigue behaviour are 1) possible concentration differences of polymer modifier within bitumen matrix, 2) presence of specific additives in the commercially produced bitumen 3) as well as the grade of the neat bitumen (before modification). It is known that the content of light fractions (maltenes) can significantly impact the properties of asphalt (Hofko et al., 2016). As it can be seen in Figure 2 and Figure 3 there exist important differences between the equipment used for the production of bituminous binders at industrial and laboratory scales, which results in a lower mixing degree in the case of laboratory-produced bitumen formulations.

Due to smaller differences between density values of SBS modifier and virgin bitumen reduced stratification is expected within the system in comparison to EOC modified bituminous composition, yielding better long-term behaviour of SBS modified bitumen, represented by fatigue tests. Consequently, SBS lab containing systems demonstrate better fatigue resistance than the EOC lab ones even at lower bitumen content and higher mixture stiffness. In line with the obtained results, the bitumen modification with SBS has been more successful. At the same time, the bitumen mixture with the EOC modifier also showed competitive results at lower strain amplitudes (up to 300 $\mu \mathrm{m} / \mathrm{m})$. 


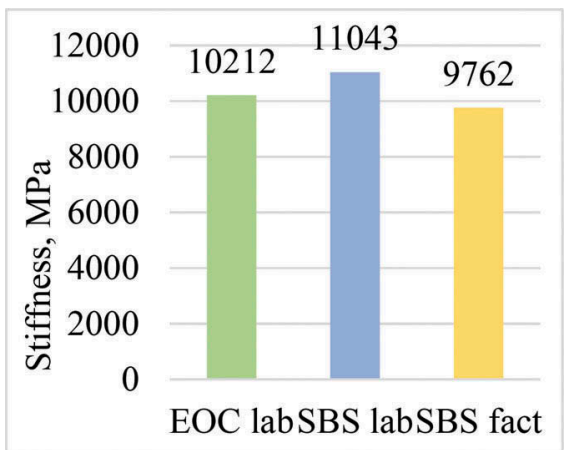

Figure 9. Stiffness modulus for all PMB asphalt mixtures.

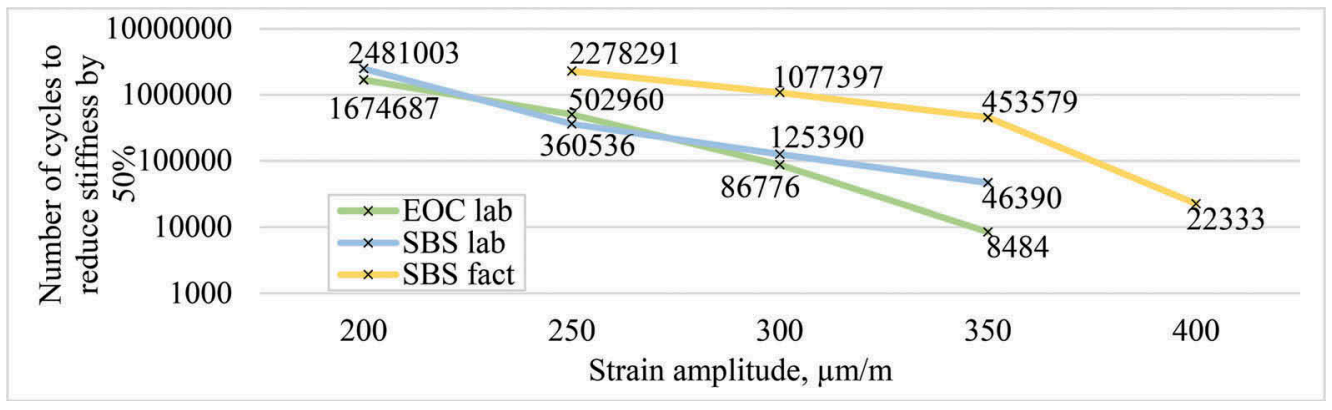

Figure 10. Fatigue strength as a function of relative deformation.

\section{CONCLUSIONS}

Test results demonstrate that in comparison to virgin bitumen the developed PMB compositions are characterized by a higher shear stress, viscosity and shear modulus values along with lower phase shift angle values, denoting a more structured system. Besides, temperature susceptibility and rutting resistance of the developed bituminous systems are improved upon the addition of the polymer modifier. Although rheological properties of both SBS based systems (SBS lab and SBS fact) denote better bituminous binder behavior within asphalt mixtures, EOC modified systems also demonstrate certain improvement in comparison to virgin bitumen. The difference between the rheological properties of SBS laband SBS fact is most probably explained by dissimilar mixing protocols, as well as unknown composition of SBS fact formulation, possibly containing specific admixtures for improvement of processability as well as compatibility within the system. Better dispersion of SBS within bitumen matrix in comparison to EOC containing systems is most probably attributed to closer density values of SBS and bitumen leading to better fatigue resistance as well as other functional properties of these systems. It is worth of mentioning that asphalt mixture with EOC modified bitumen also demonstrates good performance properties which mostly comply with the highest requirements of Latvian road specifications for wearing course.

However, further research is necessary to make EOC containing bituminous binders more competitive with SBS modified systems, particularly by addressing compatibility issues. Improvement on laboratory mixing procedure as such should be also improved (e.g. customization of the mixing head, the introduction of bitumen recirculation) to make a prediction of the properties of a factory modified bitumens more realistic. 


\section{ACKNOWLEDGEMENTS}

This study was supported by the Latvian Council of Science on the basis of the Cabinet of Ministers of the Republic of Latvia Regulation No 725 "Evaluation of Fundamental and Applied Research Projects and Administration of Finance" within the project: N०LZP-2018/ 1-0237 "Innovative use of industrial by-products for sustainable asphalt pavement mixtures".

The authors gratefully acknowledge SLLC "Latvian State Roads" for cooporation in obtaining laboratory results.

\section{REFERENCES}

Brasileiro, L., Moreno-Navarro, F., Tauste-Martínez, R., Matos, J., \& Rubio-Gámez, M. del C. (2019). Reclaimed polymers as asphalt binder modifiers for more sustainable roads: A review. Sustainability (Switzerland), 11(3), 1-20. https://doi.org/10.3390/su11030646

Hofko, B., Eberhardsteiner, L., Füssl, J., Grothe, H., Handle, F., Hospodka, M., ... Scarpas, A. (2016). Impact of maltene and asphaltene fraction on mechanical behavior and microstructure of bitumen. Materials and Structures/Materiaux et Constructions, 49(3), 829-841. https://doi.org/10.1617/s11527-015-0541-6

Isacsson, U., \& Zeng, H. (1998). Low-temperature cracking of polymer-modified asphalt. Materials and Structures/Materiaux et Constructions, 31(1), 58-63. https://doi.org/10.1007/bf02486415

Kingdom, U. (2014). CEDR Transnational Road Research Programme Call 2012: Noise: Integrating strategic noise management into the operation and maintenance of national road networks. (D).

Kragh, J., Nielsen, E., Olesen, E., Goubert, L., Vansteenkiste, S., \& De Visscher, J. (2011). OPTHINAL Optimization of Thin Asphalt Layers. Era-Net Road, (March), 82. Retrieved from http://www.brrc.be/ pdf/15/doc/OPTHINAL_FinalReport.pdf

Market Watch. (2020). Styrene Butadiene Styrene Market 2020 Size,Share Global Future Trend, Segmentation, Business Growth, Top Key Players Analysis Industry, Opportunities and Forecast to 2023. Retrieved from https://www.marketwatch.com/press-release/styrene-butadiene-styrene-market-2020sizeshare-global-future-trend-segmentation-business-growth-top-key-players-analysis-industry-oppor tunities-and-forecast-to-2023-2020-08-18

Merijs-Meri, R., Abele, A., Zicans, J., \& Haritonovs, V. (2019). Development of polyolefine elastomer modified bitumen and characterization of its rheological and structural properties. Bituminous Mixtures and Pavements VII, 52-59. https://doi.org/10.1201/9781351063265-9

Mollenhauer, K., \& Tušar, M. (2016). Functional Durability-related Bitumen Specification (FunDBitS) Identified correlations between bitumen and asphalt properties.

Ratajczak, M., \& Wilmański, A. (2020). Evaluation of laboratory methods of determination of sbs content in polymer-modified bitumens. Materials, 13(22), 1-16. https://doi.org/10.3390/ma13225237

Ren, S., Liu, X., Fan, W., Wang, H., \& Erkens, S. (2019). Rheological properties, compatibility, and storage stability of SBS latex-modified asphalt. Materials, 12(22). https://doi.org/10.3390/ma12223683

Riekstins, A., Haritonovs, V., Abolins, V., Straupe, V., \& Tihonovs, J. (2019). Life cycle cost analysis of BBTM and traditional asphalt concretes in Latvia. Engineering for Rural Development, 18. https://doi. org/10.22616/ERDev2019.18.N400

Riekstins, Arturs, Haritonovs, V., \& Straupe, V. (2020). Life cycle cost analysis and life cycle assessment for road pavement materials and reconstruction. 5, 118-135.

Singh, H., Chopra, T., Jain, S., Kaur, A., \& Kamotra, S. (2019). Effect of aggregate type and polymer modification on the performance of bituminous concrete mixes. International Journal of Applied Science and Engineering, 16(1), 1-13. https://doi.org/10.6703/IJASE.201906_16(1).001

Sol-Sánchez, M., García-Travé, G., Ayar, P., Moreno-Navarro, F., \& Rubio-Gámez, M. C. (2017). Evaluating the mechanical performance of Very Thin Asphalt Overlay (VTAO) as a sustainable rehabilitation strategy in urban pavements. Materiales de Construccion, 67(327), 1-15.

Teltayev, B. B., Rossi, C. O., Izmailova, G. G., \& Amirbayev, E. D. (2019). Effect of freeze-thaw cycles on mechanical characteristics of bitumens and stone mastic asphalts. Applied Sciences (Switzerland), 9 (3), 1-18. https://doi.org/10.3390/app9030458

VAS "Latvijas Valsts ceḷi". (2019). Ceļu specifikācijas 2019.

Zhu, J., Birgisson, B., \& Kringos, N. (2014). Polymer modification of bitumen: Advances and challenges. European Polymer Journal, 54(1), 18-38. https://doi.org/10.1016/j.eurpolymj.2014.02.005

Zicans, J., Ivanova, T., Merijs-Meri, R., Berzina, R., \& Haritonovs, V. (2019). Aging behavior of bitumen and elastomer modified bitumen. Bituminous Mixtures and Pavements VII, 47-51. https://doi.org/ $10.1201 / 9781351063265-8$ 